\title{
Euphausiid crustaceans in marine ecosystems: a contribution to the development of a new hypothesis about the role of depth on metabolic rates
}

\author{
Xabier Irigoien
}

Received: 9 December 2012/ Accepted: 12 December 2012/Published online: 9 January 2013

(C) Springer-Verlag Berlin Heidelberg 2013

The importance of synthesis papers to propose new theories is often not well appreciated in marine science. However, in a field of research where multiple factors limit the capacity of single experiments to produce novel hypothesis, synthesis papers offer a way forward in the basic scientific process of observation, hypothesis, and experimental test.

The synthesis by Ikeda (2013) on euphausiid respiration contributes data to the development of a new hypothesis about the role of depth on metabolic rates. Metabolic rates dependence on temperature and body weight are well known, and recently, a comprehensive theory has been developed (Brown et al. 2004). However, there is still variability, and it has been observed that for several groups metabolic rates also decline with depth, that is, metabolic rates at depth are lower than that what one would expect from temperature, weight or oxygen availability (Childress 1995). Based on this observation, the "visual interaction hypothesis" has been developed, proposing that metabolic rates reflect the locomotion capacities needed for predatorprey interactions that mainly depend on vision and light, and therefore, at depth, where light is limited, low energetic costs adaptations are possible (Childress 1995; Seibel and Drazen 2007). That hypothesis has been adapted by Ikeda (Ikeda et al. 2007) to apply both to organisms with functional and nonfunctional eyes: "the predation mediated selection hypothesis."

The present work by Ikeda (2013) shows that euphausiids also present a decline in metabolic rates related to

Communicated by U. Sommer.

X. Irigoien $(\bowtie)$

King Abdullah University of Science and Technology,

Thuwal, Kingdom of Saudi Arabia

e-mail: Xabier.Irigoyen@kaust.edu.sa depth, but that their metabolic rates are higher than those of copepods and chaetognaths as it could be expected by their more developed locomotion system.

Further, euphausiids are often a neglected piece in marine ecosystems. Except for the Antarctic Ocean where their relevance is obvious, euphausiids are often considered as a minor component of the ecosystem. However, there are an increasing number of papers showing their relevance in unsuspected ecosystems. For example, it has been shown now that euphausiids play a major role in the diet of the Peruvian anchoveta (Espinoza and Bertrand 2008) or that the Bay of Biscay ecosystem functioning cannot be understood without a better knowledge of the euphausiids in the system (Marquis et al. 2011). The synthesis and equations provided by Ikeda (2013) will be a keystone for any future research on the role of euphausiids in marine ecosystems.

\section{References}

Brown JH, Gillooly JF, Allen AP, Savage VM, West GB (2004) Toward a metabolic theory of ecology. Ecology 85(7):1771-1789

Childress JJ (1995) Are there physiological and biochemical adaptations of metabolism in deep-sea animals? Trends Ecol \& Evol 10(1):30-36

Espinoza P, Bertrand A (2008) Revisiting Peruvian anchovy $(<\mathrm{i}>$ Engraulis ringens $</ \mathrm{i}>$ ) trophodynamics provides a new vision of the Humboldt current system. Prog Oceanogr $79(2): 215-227$

Ikeda T (2013) Respiration and ammonia excretion of euphausiid crustaceans: synthesis toward a global-bathymetric model. Mar Biol

Ikeda T, Sano F, Yamaguchi A (2007) Respiration in marine pelagic copepods: a global-bathymetric model. Mar Ecol Prog Ser 339: 215-219

Marquis E, Niquil N, Vézina AF, Petitgas P, Dupuy C (2011) Influence of planktonic foodweb structure on a system's capacity 
to support pelagic production: an inverse analysis approach. ICES J Mar Sci 68(5):803-812

Seibel BA, Drazen JC (2007) The rate of metabolism in marine animals: environmental constraints, ecological demands and energetic opportunities. Philos Trans R Soc Lond B Biol Sci 362(1487):2061-2078 